\title{
Carnets
}

Revue électronique d'études françaises de l'APEF

Première Série - 2 Numéro Spécial | 2010

Littératures nationales: suite ou fin. Résistances, mutations \& lignes de fuite

\section{José Cervaens y Rodríguez, hispanista portugués, comentarista del poeta catalán Jacinto Verdaguer}

Ramon Pinyol i Torrents y Pere Quer i Aiguadé

\section{(2) OpenEdition}

Journals

Edición electrónica

URL: http://journals.openedition.org/carnets/5218

DOI: $10.4000 /$ carnets.5218

ISSN: 1646-7698

Editor

APEF

Edición impresa

Fecha de publicación: 1 junio 2010

Paginación: 203-214

Referencia electrónica

Ramon Pinyol i Torrents et Pere Quer i Aiguadé, « José Cervaens y Rodríguez, hispanista portugués, comentarista del poeta catalán Jacinto Verdaguer », Carnets [En ligne], Première Série - 2 Numéro Spécial | 2010, mis en ligne le 16 juin 2018, consulté le 22 avril 2019. URL : http:// journals.openedition.org/carnets/5218; DOI : 10.4000/carnets.5218 


\title{
JOSÉ CERVAENS Y RODRÍGUEZ, HISPANISTA PORTUGUÉS, COMENTARISTA DEL POETA CATALÁN JACINTO VERDAGUER
}

\author{
RAMON PINYOL I TORRENTS \\ ramon.pinyol@uvic.cat \\ PERE QUeR I Aiguadé \\ pquer@uvic.cat \\ Universitat de Vic
}

\begin{abstract}
Resumen
José Cervaens y Rodríguez dedicó a la literatura catalana un estudio en el libro Litteraturas mortas (Breves estudos sobre as litteraturas gallega, euskara, italiana e catalã, 1911). Centrado especialmente en la literatura ochocentista, presenta al público portugués la figura del escritor Jacint Verdaguer y su obra, ilustrada además con una generosa selección de textos. Jacint Verdaguer fue la personalidad más relevante del romanticismo catalán y de la "Renaixença". Fue el escritor catalán que logró una mayor proyección internacional, también en Portugal a través de las traducciones de dos de sus obras: O sonho de Sam João (1907), traducida por João Serafim Gomes, y A Atlantida (1909), traducida por José M. Gomes Ribeiro. El presente articulo analiza el conocimiento que Cervaens tuvo de Verdaguer, las fuentes bibliográficas que utilizó y los contactos que estableció para elaborar dicho estudio, especialmente con don Marcelino Menéndez y Pelayo.
\end{abstract}

\begin{abstract}
José Cervaens y Rodríguez devoted a study to the Catalan literature in the book Litteraturas mortas (Breves estudos sobre as litteraturas gallega, euskara, italiana e catalã, 1911). Essentailly focused in the XIXth century literature, Cervaens introduces the character of the writer Jacint Verdaguer to the portuguese public, as well as his works together with a wide selection of texts. Jacint Verdaguer was the most prominent figure in the Catalan Romanticism and "Reinaxença". He was the Catalan writer that achieved more international renown. Known in Portugal as well through two of his pieces: $O$ sonho de Sam João (1907), translated by João Serafim Gomes, and A Atlantida (1909), translated by José M. Gomes Ribeiro. This article analyzes Cervaens knowledge about Verdaguer, the bibliographic sources used by him and the contacts he established to prepare this study, especially with don Marcelino Menéndez y Pelayo.
\end{abstract}

Palabras clave: José Cervaens y Rodríguez, Jacint Verdaguer, literatura catalana, recepción de la literatura catalana en Portugal

Keywords: José Cervaens y Rodríguez, Jacint Verdaguer, catalan literature, reception of catalan literature in Portugal 
En 1911 apareció en Oporto un volumen que reunía estudios sobre las literaturas gallega, catalana y vasca (además de la italiana), firmado por José Cervaens y Rodríguez. Dentro de la parte dedicada a la literatura catalana, destacan marcadamente las páginas que tratan de Jacint Verdaguer y, por ello, constituyen uno de los primeros textos críticos (y el más extenso) que conocemos de la recepción de Verdaguer en Portugal ${ }^{1}$.

\section{Presentación de Jacint Verdaguer}

Jacint Verdaguer Santaló (Folgueroles [cerca de Vic, provincia de Barcelona] 1845 Vallvidrera [hoy Barcelona], 1902) es sin duda el escritor más representativo de la literatura catalana contemporánea. Por una parte, es la figura más destacada del Romanticismo catalán y la que obtuvo mayor proyección internacional en su tiempo. Por otra, es un clásico, no en el sentido de opuesto a romántico, sino en el de literato modélico, imitado, admirado y estudiado como casi ningún otro en las letras catalanas. Además, ningún otro personaje de su época no se ha mantenido como Verdaguer, "Mossèn Cinto" en la denominación popular -"mossèn" es el título de respeto dado a los sacerdotes seculares en Cataluña-, en el corazón de una gran parte del pueblo, llegándose incluso a tradicionalizarse algunos de sus poemas, que son conocidos pero ignorándose por muchos quién es su autor (es el caso del Virolai, el himno más importante cantado en honor de la Virgen de Montserrat, la patrona de Cataluña). Por ello, su caso es singular y no es extraño que en la Cataluña del siglo XXI conserve inalteradas las prerrogativas de los clásicos.

La producción literaria de Verdaguer, escrita a lo largo de cuarenta años y adscrita, como se ha dicho, a los principios románticos, se centró especialmente en la poesía, con una treintena larga de títulos, entre los publicados en vida y los póstumos. Escribió también algunas obras en prosa, de gran calidad, y realizó, en prosa y en verso, algunas traducciones y versiones de otras lenguas.

Cultivó diversos géneros poéticos (épico, bucólico, patriótico, religioso...), aunque fueron especialmente los grandes poemas épicos (L'Atlàntida y Canigó) y la literatura religiosa los que cimentaron su fama. Sobre esta última, cabe señalar que se acerca a los treinta títulos y que abarca tres grandes ámbitos: el hagiográfico, el devoto y el místico. Verdaguer, desde el momento que decidió dedicarse al sacerdocio, centró su producción en la temática religiosa y puso su actividad al servicio de la Iglesia. En este campo su trabajo fue inmenso, de tono y valor desiguales, y vehiculado a través de hojas volantes, estampas, revistas religiosas y pliegos sueltos, con lo que obtuvo gran difusión entre las masas católicas. Las necesidades devotas, apologéticas y propagandísticas del catolicismo de su

\footnotetext{
${ }^{1}$ Este estudio se enmarca en el proyecto de investigación FFI2008-04830 financiado por el Ministerio de Ciencia e Innovación de España.
} 
época determinaron que Verdaguer escribiese gran cantidad de poesía para atenderlas. Su poesía religiosa, sin embargo, no se limita a esta vertiente piadosa y apostólica, con frecuencia compuesta por motivaciones inmediatas (una polémica, una canonización, una romería, una nueva devoción, una campaña dirigida por la jerarquía...). Todo hay que decirlo, esta es la parte de su producción que se ha visto más afectada por el paso del tiempo. En las otras dos vertientes, la poesía mística y la hagiográfica, es donde el poeta muestra libros y poemas mucho más elaborados y de mayor ambición religiosa y literaria. $\mathrm{A}$ ella se refería el gran crítico español Marcelino Menéndez Pelayo cuando en su discurso de ingreso en la Real Academia Española de la Lengua sostuvo que su alta calidad hacía de Verdaguer el poeta místico español más sobresaliente del siglo XIX.

Con todo, Verdaguer era un poeta culto, voraz lector y curioso en extremo, que también desde joven se propuso realizar una obra de altos vuelos, que le diera prestigio personal, toda vez que lo diera a la literatura catalana. Por ello, el poeta dedicó, con éxito, parte de sus afanes literarios a la construcción de poemas épicos largos, de los que no podía carecer, según las preceptivas de su época, ninguna literatura que se preciase. Este aspecto, pues, no debe olvidarse en una cabal interpretación de lo significó el escritor en su momento.

A partir de la publicación de L'Atlàntida (1877), Verdaguer obtuvo una amplia difusión española e internacional, con múltiples traducciones de esta epopeya y de otros títulos que vinieron a continuación al castellano y a diversas lenguas europeas (francés, alemán, italiano, checo, occitano, portugués). Con ello, no sólo se cimentó la fama internacional de poeta, sino que también se dio a conocer la literatura catalana renaciente. Y así contribuyó de manera decisiva a consolidar el movimiento de la "Renaixença", que en la segunda mitad del siglo XIX se centró en la recuperación de la literatura culta en catalán.

Conviene recordar que este movimiento literario y cultural, auspiciado por las corrientes románticas, acabó poniendo las bases del catalanismo político -que se desarrolló a partir de la década de los ochenta-, y se dio en paralelo al renacimiento de la literatura provenzal, a la vez que sirvió de espejo para el "Rexurdimento" de la literatura gallega ochocentista.

Volviendo a Verdaguer, su prestigio también llegó a Portugal, donde a principios del siglo XX se editaron dos traducciones de obras suyas: O sonho de Sam João. Lenda lyrica do Coraçao de Jesus (Verdaguer, 1907), en versión del jesuita João Serafim Gomes, i $A$ Atlántida (Verdaguer, 1909), a cargo de José M. Gomes Ribeiro, profesor del Colegio de Campolide. La primera se enmarca en las campañas de difusión de la devoción al Sagrado Corazón de Jesús emprendidas por la Iglesia católica. Se trata de una simple traducción, sin ninguna información ni sobre el autor ni sobre su producción. La segunda, la obra más famosa de Verdaguer, se debe a la iniciativa del traductor, un devoto entusiasta del poeta 
catalán, que la hace preceder de un prólogo de trece páginas donde da a conocer al autor, comenta la importancia de la epopeya que traduce y demuestra que conoce a los principales críticos y traductores castellanos de la obra. Ambas traducciones, junto con el libro de Cervaens de que trataremos seguidamente, constituyen la parte más notable, que sepamos, de la recepción de Verdaguer en Portugal en las dos primeras décadas del siglo XX.

\section{José Cervaens y Rodríguez}

No existe, que sepamos, ninguna biografía de este escritor. Trataremos, de todas maneras, de trazar unos mínimos apuntes de su trayectoria vital, a partir, básicamente, de lo que él mismo cuenta en sus obras y en unas cartas dirigidas a Menéndez Pelayo.

Nacido hacia 1870 en Oporto, descendiente de españoles, cuenta él mismo que se dio a conocer con la publicación de unas Breves consideraciones sobre la Colonia Española residente en Oporto, que no hemos conseguido localizar. La obra mereció — según él mismo dice- grandes alabanzas en la prensa portuense pero al parecer algunas entidades se sintieron ofendidas por el escrito y por su relieve en los diarios. La ciudad estaba ya en los prolegómenos de la primera Revolución republicana, el alzamiento militar del 31 de enero de 1891. Cuando éste se produjo, Cervaens fue acusado de secundar el movimiento, fue conducido al puerto de Leixões y preso a bordo del Moçambique.

Nunca Cervaens nombra exactamente cuál o cuáles pudieran ser las entidades que con tanta inquina le trataban. De todos modos, en nuestra mente se ha formado la idea de que la persecución que él refiere podría deberse a cuestiones de índole política ${ }^{2}$. Si a esto se le une, además, su origen foráneo y la posición vindicativa expresada en la publicación que le dio a conocer, es fácil pensar que se le relacionara rápidamente con los partidarios de la revolución antimonárquica. Lo cierto es que por miedo a las represalias personales optó por exiliarse en Galicia.

El exilio no fue largo, como dice él mismo. En 1893 le encontramos de nuevo en Oporto vinculado al semanario $A$ Cidade do Porto, de clara filiación republicana, donde publica notas biográficas de personajes de actualidad (4) y poemas (6) en los primeros 6 números aparecidos. Firma las colaboraciones con sus apellidos o con el pseudónimo 'Sneavrecy'. En 1894 figura como redactor gerente de una publicación semanal llamada La Unión Española, que se presentaba como el órgano de la colonia española en Portugal. En ella publicó principalmente poesía (3), siempre en portugués.

\footnotetext{
${ }^{2}$ El trabajo de Cervaens como divulgador de las culturas españolas tiene como trasfondo las ideas iberistas. Más adelante le encontraremos mencionado en relación con el movimiento mutualista, importante en Oporto y enlazado, a su vez, con el movimiento obrero.
} 
Un año después vio la luz una Grammatica Hespanhola Theorico-Prática para uso dos portuguezes, debida a su pluma (Cervaens, 1895). La característica más destacable de esta obra es que introduce en la enseñanza de lenguas el procedimiento de la traducción interlineal. Entre 1895 y 1901 debió de dedicarse principalmente a la enseñanza. Años más tarde, él mismo decía que trabajaba en los estudios literarios en ratos robados al descanso que le exigía el "tormentoso mester de desbravar cerebros infantiles" (Menéndez Pelayo, 1988: vol. XVI, p. 70). Probablemente tuvo dificultades para sacar adelante a su familia. Por lo menos esto es lo que dice en su primera carta a don Marcelino Menéndez y Pelayo del 4 de mayo de 1901 en la que le expresa —en una increíble mezcla de barroca ampulosidad, excesiva sumisión e inmediata cotidianidad- las dificultades en las que se encuentra. Tantas son, que le solicita si puede regalarle algunas de sus obras.

En la carta revela algunos aspectos de su vida. En primer lugar, se autoproclama varias veces español. A continuación, se describe como "profesor de lenguas y periodista" y destaca por encima de todo sus dificultades económicas con expresivas exclamaciones como: "Pero soy pobre...", "Dinero para libros —Dios mío- no lo tengo", o el casi desesperado "Y yo que acabo de recibir la visita del dueño de la casa para cobrar el importe del alquiler de la casa y que he quedado con 7 duros para los gastos mensuales...". Recordemos que Cervaens escribe en el día cuarto del mes. Sea exagerado o no su retrato, hay que destacar la mención a su relación con Carolina Michaëlis de Vasconcellos, lo que indica algún contacto (no sabemos en qué grado) con los círculos intelectuales y filológicos de Oporto.

Mientras tanto, su dedicación a la literatura es patente porque en el mismo año publicó su primera obra como estudioso, Atravez da Hespanha litterária: breves estudos sobre a litteratura hespanhola antiga e moderna (Cervaens, 1901), que es un mosaico de pequeñas notas sobre autores variados, en los que no sabemos ver ningún criterio claro de selección ni de enfoque.

Una segunda carta, sin fecha ${ }^{3}$, dirigida a don Marcelino Menéndez y Pelayo es la siguiente referencia que podemos dar sobre José Cervaens (Menéndez Pelayo, 1988: vol. XVII, pp. 556-557). Lleva sello del "Instituto de Educação para ambos os Sexos" de Oporto. Su tono es muy distinto, ya que le formula simplemente una petición. Sigue, pues, con sus ocupaciones literarias, que dan como fruto la obra Litteraturas mortas (Cervaens, 1911), sobre la que hablamos más adelante. Todavía existe una tercera carta a Menéndez y Pelayo, que data del 6 de agosto de 1911, cuando parte del volumen ya está en prensa (Menéndez Pelayo, 1988: vol. XXI, p. 444). Esta tercera carta es muy relevante para nuestro propósito ya que en ella Cervaens le pregunta en concreto sobre la literatura catalana, de la

\footnotetext{
${ }^{3}$ De 1904 según Manuel Revuelta, editor del Epistolario de don Marcelino Menéndez y Pelayo.
} 
que, según dice, "no conozco gran cosa" y le ruega información o pistas sobre Antoni de Bofarull y sobre Santiago Rusiñol. También le solicita si "podría V.E. proporcionarme a vuelta de correo el libro de Miguel Santos Oliver que trata de don Mariano Aguiló". Al fin, solicita indicación de alguna otra fuente general sobre la cuestión para añadir a la que él ya conoce: "Ya poseo el libro del P. Blanco García sobre las literaturas regionales (III tomo). Deseaba otro cualquiera que V.E. viese que me podría servir de más desarrollo".

En esa tercera carta, Cervaens vuelve a presentarse otra vez a don Marcelino Menéndez y Pelayo. La presentación tiene esta vez un tono muy diferente al que Cervaens le dio en 1901: ha dejado de presumir de español; eso sí, continúa siendo divulgador en Portugal de todo lo que concierne a las letras españolas, "ya por la pluma, ya por la palabra". Esta última referencia a la palabra podría surgir de su labor docente o quizá también de su progresiva dedicación a los discursos y conferencias, actividad en la que producirá bastante en los años siguientes.

Efectivamente, en lo que hemos podido recoger de la producción de Cervaens a partir de Litteraturas mortas predominan las memorias, conferencias o discursos. Sobre las letras brasileñas (1914), sobre la pintura contemporánea (1915), sobre los exploradores portugueses Gonçalo Velho y Magallães (1922) o sobre Rosalía Castro (1924). Completan la lista una conferencia sobre Literatura Italiana de la que no sabemos la fecha y un discurso leído en el $31^{\circ}$ aniversario de la "Associação Protectora da Infancia" (1934). Entremedias, publicó una segunda edición de Litteraturas mortas? (1921).

\section{Litteraturas mortas?, de José Cervaens y Rodríguez}

En 1911 aparecía el libro Literaturas mortas (Breves estudos sobre as literaturas gallega, euskara, italiana e catalã), publicado por la Livraria Portuense de Lopes \& $\mathrm{C}^{\underline{a}}$ Successor-Editor (Cervaens, 1911). Se trata de un tomo de 388 páginas, del que, de entrada, sorprenden en el título la falta de un signo de interrogación —-dado que el libro pretende demostrar todo lo contrario- y en el subtítulo la inclusión de la literatura italiana, de la que en modo alguno se puede decir que hubiera estado muerta o en trance de muerte. El primer aspecto, resulta explicado por el autor en la segunda edición, publicada en 1921 también en Oporto, esta vez por la Companhia Portuguesa Editora:

O título que o original continha, era Literaturas Mortas? e justificava-se, por não estarme actualisadas no nosso meio as quatro grandes almas colectivas de que tratam estes modestos estudos, no momento em que êles eram trazidos á luz da publicidade. O que nunca se justificará, é a eliminação do sinal interrogativo que, 
apesar das instantes chamadas feitas pelo auctor, os senhores tipógrafos teimaram em sustentar, contrariando-lhe assim a ideia.

Estando ausente o auctor quando foram postos à venda estes estudos, não pôde evitar que aparecessem com esta lamentable lacuna. Que a crítica e os leitores cultos a relevem com a mesma paciencia com que o auctor suportou injustos reparos a que ela deu causa. (Cervaens, 1921: 389)

Esta segunda edición se abre con diez páginas de comentarios aparecidos en la prensa y de cartas de personalidades a las que el autor envió el libro. Como en la primera edición, contiene dedicatorias a personajes relevantes de la política portuguesa y española. No se trata, sin embargo, de una edición revisada, dado que reproduce fielmente la primera, con la misma composición de las páginas, limitándose a añadir, con numeración romana al inicio, los comentarios a que hemos aludido, y al final del libro unas breves páginas con una relación, prácticamente sin valoraciones, de nombres de autores vascos y catalanes no recogidos en la primera edición.

En las dos ediciones, Cervaens afirma en una breve nota inicial, "Ao leitor", que la finalidad principal de su obra, producto de arduo a la vez que placentero trabajo, es el de dar a conocer unas literaturas "originalissimas", cuyos autores y sus obras más notables merecen ser divulgados por sus "merecimentos excepcionaes".

\section{AO LEITOR}

Não é pela ancia, que nunca me cégou, de ver cingido o meu nome humilde d'uma aureola litteraria refulgente, que este despretencioso libro sae a lume.

Producto d'algumas horas de arduo, embora deleitoso trabalho, furtivamente roubadas á labuta cuotidiana, elle ficaria perpetuamente encerrado na minha gaveta e desconhecido do publico que lê, se a consciencia me não segredasse que, dando-o á estampa, algum serviço prestava ás letras e muito particularmente áquelles povos de que trata.

Com effeito, nas desataviadas paginas, que a seguir vão, encontrará o leitor curiosos informes, ao parecer novos e interessantes, acêrca das originalísimas literaturas catalã, gallega, italiana e vasca, com um estudo, conscienciosamente feito, sobre a lingua e marcha evolutiva dos povos respectivos.

Ahi se tornam conhecidos -e é este o escopo principal da obra- os seus monumentos litterarios mais notaveis e caracteristicos e os seus escriptores mais illustres, apreciando-os á luz clara d'um são criterio e collocando-os na plana a que thes crearam jus os seus merecimentos excepcionaes.

Não é, pois, "movido de premio vil" mas impulsionado por un alto sentimento de justiça social, que todo o homem deve ufanar-se de possuir, que eu me abalanço a submetter aos rigores da Critica o presente estudo sobre "Litteraturas mortas". 
Que a isto attenda o zoilo mordaz, que do apreciador sincero e justiceiro se não arreceia.

O Auctor.

(Cervaens, 1911: 11-12)

La parte dedicada a la literatura gallega (unas cincuenta páginas), donde hay, además, algunas referencias autobiográficas del autor, es un repaso muy sumario sobre la historia literaria galaica, que concluye con una generosa antología de textos. También amplia es la selección de textos vascos, con su correspondiente traducción portuguesa, en la parte dedicada a la literatura en euskera (casi noventa páginas), centrada en escritores y escritoras de los siglos XVIII y XIX, con abundantes citaciones en vascuence de las que no ofrece traducción.

La parte italiana es la más sorprendente. Sus sesenta páginas están dedicadas, por mitad, a los líricos ochocentistas (pasa muy por encima de la narrativa) y a cuatro escritoras (Grazia Deledda, Ada Negri, Teresa Ubertis y A. Rosselli, hoy prácticamente desconocidas estas dos últimas). En parte alguna no justifica la inclusión de la literatura italiana en el libro, dado que no hubo ningún "renacimiento" porque no se había producido ninguna decadencia de las letras italianas y el Risorgimento, como es sabido, fue político y no literario.

La parte más extensa es la consagrada a las letras catalanas (ciento setenta y ocho páginas). Mantiene un cierto equilibrio entre las épocas y contiene una relativa variedad de fuentes bibliográficas (básicamente de la crítica española), aunque, a parte de largos fragmentos de Verdaguer, de los que trataremos después, no incluye ninguna selección de textos como las que ofrecen las páginas centradas en las literaturas gallega y vasca. Con todo, Cervaens da una visión global bastante aceptable de lo que habían sido históricamente las letras catalanas y de lo que había representado la Renaixença en el siglo XIX. Todo hay que decirlo, en algunos casos traduce literalmente durante páginas - sin indicarlo expresamente- de fuentes historiográficas o críticas en lengua española, procedimiento que, a lo que parece, no fue detectado en su época.

\section{Jacint Verdaguer en Litteraturas mortas?}

La parte del libro dedicada a Jacint Verdaguer (Cervaens, 1911: 300-334) ofrece información sobre las obras más importantes del poeta y una visión de su figura bastante completa. Para componer esta parte Cervaens maneja tres fuentes, una de las cuales no hemos podido identificar. Lo más destacable de su trabajo con las dos restantes, españolas las dos, es precisamente la absoluta dependencia que presenta de ellas. 
La primera es una historia de la literatura del Padre Francisco Blanco García, agustino, llamada La literatura española en el siglo XIX (Madrid, Sáenz de Jubera, 1894) que, en el tomo tercero, trataba de las literaturas "regionales". El apartado que dedica a Verdaguer aparece casi íntegramente traducido punto por punto en la obra de Cervaens. Se puede decir, pues, que "importa” el artículo del Padre Blanco García.

A éste le une otro texto, en este caso de Josep Pijoan, aparecido en el número de marzo de 1906 de la revista madrileña La lectura, con el título "Las obras inéditas de Mosén Jacinto Verdaguer" (Pijoan, 1906). En el artículo, Pijoan repasa las obras del poeta narrando en primera persona y con sumo detalle la experiencia de haber sido uno de los encargados de ordenar los papeles de Verdaguer después de su muerte. De ahí que Cervaens ofrezca información tan detallada de la obra póstuma del poeta catalán.

Aunque los dos trabajos mencionados son citados en algún momento, en Litteraturas mortas Cervaens se limita prácticamente a traducirlos. A penas en un par de lugares se aparta un poco de ellos para resumir o adaptar el texto. Especialmente en un pasaje oscuro del Padre Blanco García y más a menudo en el texto de Pijoan — tan personal— en el que cambia el punto de vista narrativo a tercera persona, no sin algunos errores ${ }^{4}$.

Cuando su fuente ofrece citaciones textuales de los versos de Verdaguer, Cervaens los transporta también. Si en ellas existe traducción al español, las traduce al portugués; no así cuando sólo aparecen en catalán.

Hemos hablado de una tercera fuente no identificada. De ella debió de salir la larga citación textual del Canigó de Verdaguer, en catalán, que Cervaens ofrece (1911: 310-328). El fragmento constituye el canto IV de la obra y consta de dos poemas: Lo Pirineu y La malehida. Este título es lo único que Cervaens trasladó al portugués ('A Malfadada').

El largo fragmento es introducido al hilo de un comentario del Padre Blanco García sobre Lo Pirineu. Dicho comentario se basa en otro artículo, éste de Ramón D. Perés (Perés, 1892: 258-293) donde no aparece el fragmento en cuestión. Por lo tanto, Cervaens tuvo acceso a algún texto del Canigó en catalán. En 1911 solamente se puede suponer que tuviera a mano una de las dos ediciones de la obra que estaban en circulación (la de 1886 o la de 1901) o bien la traducción francesa de Tolrà de Bordas, de 1889, que sí incorporaba el texto catalán.

\footnotetext{
${ }^{4}$ Por ejemplo cuando Cervaens escribe: "Santo Antonio segue assim fallando com bondade rustica no vulgar romance do nosso povo" (1911: 334). La frase se refiere, obviamente, a la lengua catalana, y el posesivo nosso utilizado aquí constituye un despiste que demuestra el estrechísimo ceñimiento con el que transportó el artículo de Pijoan. También se observan dos errores más: en la denominación de la obra Pastoral, que en realidad debería ser Santoral (Cervaens, 1911: 333) y en la traducción del español al portugués de unos versos dónde confundió "sanar" por "amar" (Cervaens, 1911: 307).
} 
Creemos plausible que alguno de los españoles residentes en Oporto, con los que Cervaens debía de mantener contactos, poseyera un ejemplar de la obra ${ }^{5}$. Tendría que estudiarse ese aspecto concreto de la actividad cultural de dicha colonia, quizá aglutinada alrededor de lo que era el "Centro Español de Oporto". O también es posible que algún informador le hubiera copiado estas páginas en correspondencia privada.

No sabemos si de la misma fuente podría ser el fragmento introductorio que usa como presentación de Jacint Verdaguer (Cervaens, 1911: 300-301). Este texto, altamente retorizado, contiene una descripción muy detallada de la escena del triunfo de Verdaguer en los Jocs Florals de Barcelona de 1877. Dicha descripción tuvo una cierta circulación en reseñas, artículos y comentarios de revistas literarias y es en ese campo donde debemos asignar, sin duda, el origen de las palabras que Cervaens coloca como presentación de Verdaguer.

Paralelamente a su dependencia de las dos fuentes indicadas y de la existencia de una tercera, hay que destacar - al mismo nivel de importancia - el hecho de que Cervaens no tenga para nada en cuenta las dos traducciones de Verdaguer que en ese momento circulaban en Portugal y que ya hemos mencionado. Ello nos indica más claramente, si cabe, que en el caso de la literatura catalana la obra de Cervaens no partió de conocimientos previos sino que se trata de la compilación y puesta en circulación de fuentes y estudios españoles que, de algún modo, llegaron a sus manos. Cervaens cumplía así su "servicio" a las culturas de las literaturas estudiadas, objetivo anunciado en el prólogo del libro.

Eso no significa que no se esforzase por conseguir para su trabajo las fuentes mejores y más modernas. Son prueba de que lo hacía los intentos que realizó en varias ocasiones para contactar con el referente crítico por antonomasia de las literaturas españolas, don Marcelino Menéndez y Pelayo. Precisamente en su tercera carta le indica que tiene ya en prensa parte de Litteraturas mortas y confiesa que dispone del libro del Padre Blanco. No sabemos si las otras fuentes que utilizó, por lo menos el artículo citado de Pijoan, pudiera habérselas proporcionado el propio Menéndez y Pelayo...

Las páginas que Cervaens dedicó a Jacint Verdaguer se construyeron del modo que hemos señalado. No contienen, pues, ninguna aportación propia: ni interpretativa, ni de perspectiva ideológica, ni de síntesis. Nuestro autor llevó a cabo una tarea meramente compilativa, juntando algunas piezas que había obtenido. Aún así, cumplió con su objetivo de dar a conocer las literaturas estudiadas $y$, en concreto, al más alto poeta de la Renaixença catalana.

\footnotetext{
${ }^{5}$ Suponemos que debía de mantener ciertos contactos desde su época como redactor en distintas publicaciones dirigidas a los españoles residentes en Oporto.
} 
En definitiva, José Cervaens y Rodríguez, hispanista portugués, es una figura de una cierta relevancia sobre la que hay escasa información. Para nuestro foco de interés, la recepción de Jacint Verdaguer en Portugal, es un personaje significativo, pero faltan estudios específicos que lo sitúen en su contexto, en el seno de la sociedad portuense de principios del siglo XX. Esperamos poder profundizar un poco más en ello en el futuro. 


\section{Bibliografía}

BLANCO GaRCíA, Francisco (1894). La literatura española en el siglo XIX. Madrid: Sáenz de Jubera.

Cervaens y RodríGuez, José (1895). Grammatica Hespanhola Theorico-Prática para uso dos portuguezes. Porto: Livraria Chadron.

Cervaens y RodríGueZ, José (1901). Atravez da Hespanha litterária: breves estudos sobre a litteratura hespanhola antiga e moderna. Porto: Tip. da Empreza Litteraria e Typographica.

CERVAENS y RODRíGUEZ, José (1911). Literaturas mortas (Breves estudos sobre as literaturas gallega, euskara, italiana e catalã). Porto: Livraria Portuense de Lopes \& Cํㅗ Successor-Editor.

CERVAENS y RODRíGUEZ, José (1921). Litteraturas mortas (Breves estudos sobre as literaturas gallega, euskara, italiana e catalã). 2ª ${ }^{\mathrm{a}}$. ed. Porto: Companhia Portuguesa Editora.

MENÉNDEZ y PELAYO, Marcelino (1988). Epistolario. Edición de Manuel Revuelta. Madrid: Fundación Universitaria Española, 1988-1989.

Perés, Ramon D. (1892). A dos vientos: críticas y semblanzas. Barcelona: L’Avenç.

PIJOAN, Josep (1906). "Las obras inéditas de Mosén Jacinto Verdaguer". In: La lectura, marzo 1906, pp. 261-271. [Hemos seguido la transcripción de Anna M. BLASCO BARDAS. "Josep Pijoan i Jacint Verdaguer”. In: Anuari Verdaguer, 1993-1994, pàg. 295-323, apéndice IV. También accesible en línea en http://www.raco.cat/index.php/AnuariVerdaguer/article/view/67662/86106 [consulta 8-22010]

VeRDAGUER, Jacint (1907). O sonho de Sam João. Lenda lyrica do Coraçao de Jesus. Trad. de João Serafim Gomes. Fafe: Propaganda Católica.

VerdagueR, Jacint (1909). A Atlántida. Trad. de José M. Gomes Ribeiro. Lisboa: Livraria FerinEditora. 